\title{
A multi-purpose reaction cell for the investigation of reactions under solvothermal conditions
}

N. Heidenreich, U. Rütt, M. Köppen, A. Ken Inge, S. Beier, A.-C. Dippel, R. Suren, and N. Stock

Citation: Review of Scientific Instruments 88, 104102 (2017);

View online: https://doi.org/10.1063/1.4999688

View Table of Contents: http://aip.scitation.org/toc/rsi/88/10

Published by the American Institute of Physics

\section{Articles you may be interested in}

Development of a spectro-electrochemical cell for soft X-ray photon-in photon-out spectroscopy

Review of Scientific Instruments 88, 104101 (2017); 10.1063/1.4997820

Switched ratiometric lock-in amplifier enabling sub-ppm measurements in a wide frequency range Review of Scientific Instruments 88, 104704 (2017); 10.1063/1.4996423

X-ray spectrometer having 12000 resolving power at 8 keV energy

Review of Scientific Instruments 88, 103107 (2017); 10.1063/1.4999995

Hardware for dynamic quantum computing

Review of Scientific Instruments 88, 104703 (2017); 10.1063/1.5006525

An optical fiber Bragg grating and piezoelectric ceramic voltage sensor

Review of Scientific Instruments 88, 105005 (2017); 10.1063/1.4986046

Controlled removal of micro/nanoscale particles in submillimeter-diameter area on a substrate

Review of Scientific Instruments 88, 105003 (2017); 10.1063/1.4998617

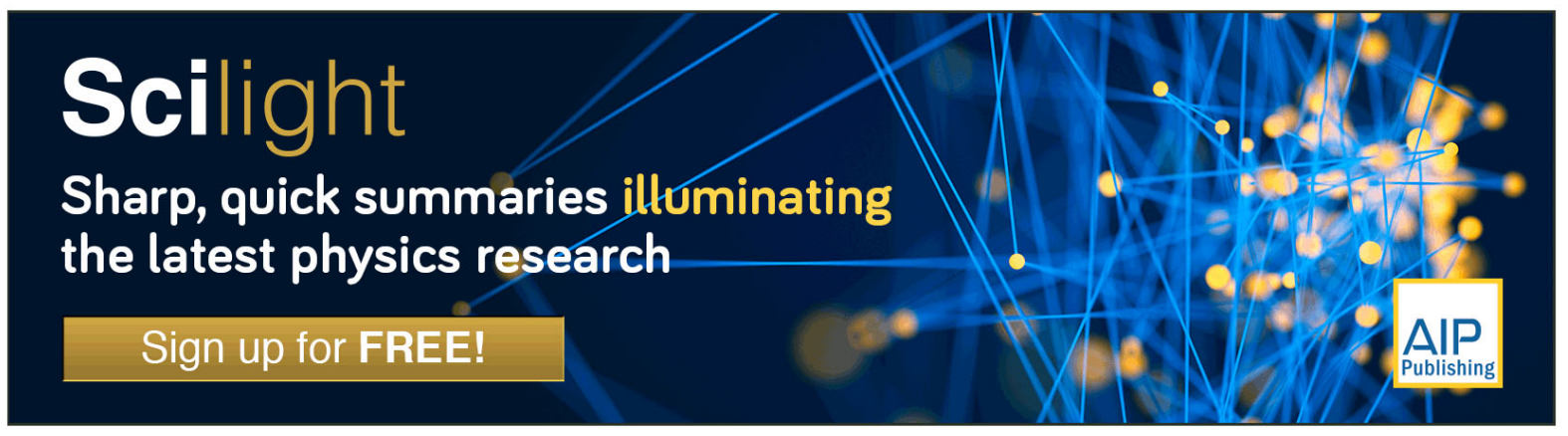




\title{
A multi-purpose reaction cell for the investigation of reactions under solvothermal conditions
}

\author{
N. Heidenreich, ${ }^{1,2}$ U. Rütt, ${ }^{2}$ M. Köppen, ${ }^{1}$ A. Ken Inge, ${ }^{3}$ S. Beier, ${ }^{1}$ A.-C. Dippel, ${ }^{2}$ R. Suren, ${ }^{1}$ \\ and N. Stock ${ }^{1, a)}$ \\ ${ }^{1}$ Institut für Anorganische Chemie, Christian-Albrechts-Universität zu Kiel, Kiel 24118, Germany \\ ${ }^{2}$ Deutsches-Elektronen-Synchrotron DESY, Notkestraße 85, 22607 Hamburg, Germany \\ ${ }^{3}$ Department of Materials and Environmental Chemistry and Berzelii Center EXSELENT on Porous Materials, \\ Stockholm University, Stockholm S-106 91, Sweden
}

(Received 10 August 2017; accepted 6 October 2017; published online 20 October 2017)

\begin{abstract}
A new versatile and easy-to-use remote-controlled reactor setup aimed at the analysis of chemical reactions under solvothermal conditions has been constructed. The reactor includes a heating system that can precisely control the temperature inside the reaction vessels in a range between ambient temperature and $180^{\circ} \mathrm{C}$. As reaction vessels, two sizes of commercially available borosilicate vessels $\left(\mathrm{V}_{\max }=5\right.$ and $\left.11 \mathrm{ml}\right)$ can be used. The setup furthermore includes the option of stirring and injecting of up to two liquid additives or one solid during the reaction to initiate very fast reactions, quench reactions, or alter chemical parameters. In addition to a detailed description of the general setup and its functionality, three examples of studies conducted using this setup are presented. Published by AIP Publishing. https://doi.org/10.1063/1.4999688
\end{abstract}

\section{INTRODUCTION}

For an efficient reaction design, it is vital to understand the underlying process of chemical reactions. With conventional laboratory methods that rely on quenching or solely analyzing the end-product of a reaction, only a snapshot of the reaction progress is obtained, revealing little information about the reaction mechanism. Consequently to optimize a reaction following this approach, it is often necessary to empirically improve the reaction parameters for a more efficient synthesis. Contrary to these ex situ methods, in situ ${ }^{1}$ and operando ${ }^{2}$ techniques allow for the analysis of chemical reactions while they are occurring, providing substantially more information about active species or short-lived intermediate phases that play a significant part in the reaction process. ${ }^{3-5}$ Even though some methods exist that enable the examination of chemical reactions in situ in a laboratory environment, ${ }^{6-8}$ the majority of very powerful techniques is X-ray based and requires synchrotron radiation with higher energy and intensity compared to laboratory sources. Such radiation is only available at a few facilities and allows penetration of reaction chambers and solvent volumes as well as fast measurements to follow reactions. These methods involve X-ray diffraction (XRD), ${ }^{9-13}$ X-ray absorption spectroscopy (XAS), ${ }^{14,15}$ small-angle X-ray scattering (SAXS), and total scattering and pair distribution analysis (PDF) ${ }^{15-17}$ that are universally applicable and allow analysis of a diverse spectrum of chemical compounds and materials. With the development of 3 rd generation synchrotron sources and better detectors, the prospects of in situ analyses have dramatically increased, yielding a far better time resolution and signal quality. Nevertheless the conditions for chemical reactions are diverse, ranging from ambient to highpressure and static to dynamic conditions, while the laboratory

a)stock@ac.uni-kiel.de setting cannot easily be transferred to the beamline in most cases. Hence each type of reaction requires the construction of an appropriate reaction cell prior to the experiment. Furthermore each analysis technique imposes its own limitations and prerequisites that have to be addressed in the design of the reaction cell. In the field of crystalline porous materials, for instance, the synthesis is mostly carried out under solvothermal conditions, meaning at temperatures above the boiling point of the employed solvent in a closed container. For the analysis of reactions under solvothermal conditions, only a few specialized reaction cells have already been applied in the area of in situ analysis using X-ray based methods. ${ }^{18-23}$ Each one of these reactor setups has specific advantages but does not combine capabilities like high-precision temperature adjustment and dosing combined with a remote controlled operation, while closely mimicking laboratory conditions. The combination of these capabilities is necessary to carry out a broad range of different reactions.

As each analysis technique only provides a part of the information required to entirely understand the mechanism of a chemical reaction, it is often necessary to combine several characterization techniques. ${ }^{1,5,6,14,15,17}$ In consideration of this, it is ideal to use a reaction cell that can be utilized for different analysis techniques to avoid introducing any new parameters like changes in volume, shape of cell, and stirring efficiency that might change when shifting to a different experimental setup. Additionally the reaction cell should be easy to operate while working as close as possible to laboratory conditions to ensure that the results from previous ex situ investigations can be reproduced well.

In this paper, we present a reaction cell that was constructed at CAU Kiel (Christian-Albrechts-University Kiel) in cooperation with the staff of beamline P08, ${ }^{24}$ PETRA III, DESY. The cell is suited for the in situ analysis of chemical reactions under ambient and solvothermal conditions up 
to $180{ }^{\circ} \mathrm{C}$. The focus of this reaction cell lies in the design of an easy-to-use and versatile reactor that closely mimics the conditions present in a common laboratory. In addition, the reactor setup provides an injection system and a solid dosing device that can be used to initiate and quench reactions or alter chemical parameters during a reaction.

\section{APPARATUS}

\section{A. Reactor setup}

The reactor setup SynRAC (synchrotron-based reaction cell for the analysis of chemical reactions) was developed in a cooperation between the CAU Kiel and Deutsches ElektronenSynchrotron DESY. The whole setup (Fig. 1) encompasses different components in addition to the reaction cell. In Secs. II B-II I, the interplay between these components is described in detail to illustrate the functionality of the reactor setup.

\section{B. Design of the in situ cell}

The centerpiece of SynRAC (Fig. 1) consists of an aluminum casing that can accommodate two sizes of borosilicate reaction vessels. The casing is $880 \mathrm{~mm}$ long with an inner diameter (ID) of $161 \mathrm{~mm}$ and is composed of anodized aluminum to improve heat transfer to the reaction vessels. It is centered on a $55 \mathrm{~mm} \times 55 \mathrm{~mm} \times 14 \mathrm{~mm}$ socket that encases a $48 \mathrm{~mm} \times 48 \mathrm{~mm} \times 17 \mathrm{~mm}$ electromagnetic stirrer (stirrer: MIXdrive $1 \mathrm{XS}, 2 \mathrm{mag}$; control station: MIXcontrol eco, $2 \mathrm{mag}$ ). The stirrer can agitate the sample with an adjustable stirring rate up to a speed of $1200 \mathrm{rpm}$. A socket and stirrer are fixed on a ground plate to mount the cell on the beamline in transmission geometry. The ground plate provides a $100 \mathrm{~mm} \times 100 \mathrm{~mm}$ hole grid that is commonly used at various beamlines.

Surrounding the aluminum casing, a mantle of coppergalvanized heating wires is installed to heat the sample to the target temperature. A protective cage around the heating system avoids any injury to users due to hot surfaces.

As the reaction cell is to be mounted in transmission geometry, the synchrotron beam penetrates the cell in the center at a

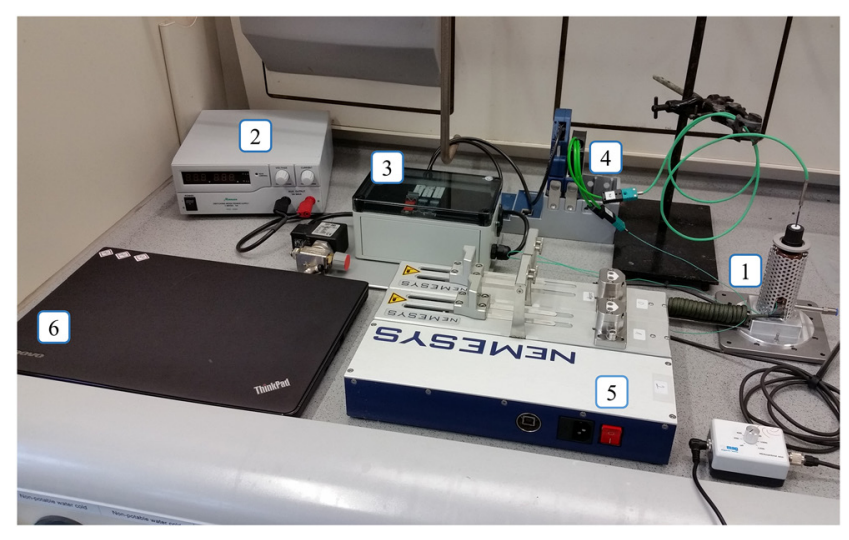

FIG. 1. Overview of the reactor setup including the reaction cell (1), power supply (2), electronic relay box (3), and compact chassis (4) associated with the heating system as well as a syringe pump system (5) and the laptop used to control the setup (6). height of $50 \mathrm{~mm}$ above the ground plate. In this area, the aluminum casing has been thinned out to a thickness of $100 \mu \mathrm{m}$. This ensures that a beam intensity loss due to the absorption of the aluminum windows is minimized while the thickness is still sufficient to contain any liquids in the case of a reaction vessel burst (Sec. II E). A close-up view of the entrance and exit windows is shown in Fig. 2 on the right. The entrance window has a length of $9.5 \mathrm{~mm}$ and a width of $3 \mathrm{~mm}$, and the exit window has a length of $27 \mathrm{~mm}$ and a width of $5 \mathrm{~mm}$, respectively. The windows are kept as small as reasonably possible to ensure a high temperature stability. A representational picture of the centerpiece is included in the supplementary material (Fig. S1).

As reaction vessels (Fig. 3), two different sizes of borosilicate glass vials $\left(\mathrm{V}_{\max }=5 \mathrm{ml}\right.$ and $\left.\mathrm{V}_{\max }=11 \mathrm{ml}\right)$ can be used. The small vessels $\left(\mathrm{V}_{\max }=5 \mathrm{ml}\right)$ are $\sim 100 \mathrm{~mm}$ long with an inner diameter of $\sim 10 \mathrm{~mm}$ and a wall thickness of $1 \mathrm{~mm}$.

The bigger vessels are $\sim 100 \mathrm{~mm}$ long with an inner diameter of $\sim 15 \mathrm{~mm}$ and an approximate wall thickness of $1.5 \mathrm{~mm}$. Change between the two sizes of glass vessels is easily possible with a reduction inset made from anodized aluminum.

These types of reaction vessels were selected as they are commercially available, low priced and are already frequently used in laboratory practice.$^{25,26}$ In the case of an in situ analysis of a chemical reaction, it is advisable to investigate the reaction system thoroughly prior to the beamtime using ex situ methods to develop an understanding of the reaction progress and the influence of different parameters on the product formation. For some reactions, however even minor parameter changes like a different composition of the reaction vessel (glass or PTFE, Polytetrafluorethylen) or a variation in the surface-to-volume ratio can already influence the outcome of the experiment. Therefore it is preferable to use vessels that come close to the ones used for the ex situ experiments or if possible, even the same ones. Another major advantage of using cheap, disposable reaction vessels lies in the fact that cleaning of the cell is not required after every reaction. Once an experiment is completed another reaction vessel prepared beforehand can easily be inserted into the cell and analyzed without disassembling the cell or realigning it. This saves precious time at the synchrotron and excludes the influence on the reaction due to trace amounts of chemicals related to a previous reaction.

\section{Heating system}

In the field of crystalline porous materials, the synthesis temperatures reported in the literature extend up to temperatures of $\sim 180{ }^{\circ} \mathrm{C}$. Consequently to span the whole range of different reported reactions, we aim for a maximum operating temperature of $180{ }^{\circ} \mathrm{C}$. Heating the reaction mixtures is accomplished by resistive heating using a mantle comprised of copper-galvanized heating wires surrounding the casing holding the borosilicate vessels. The accessible temperature range currently lies between ambient temperature and $180^{\circ} \mathrm{C}$ measured in the reaction vessel. The heating mantle is connected to a maximum $60 \mathrm{~V} / 15$ A power supply (HCS-3604, Reichelt) that is operated in a pulsed mode. For a more precise control of 


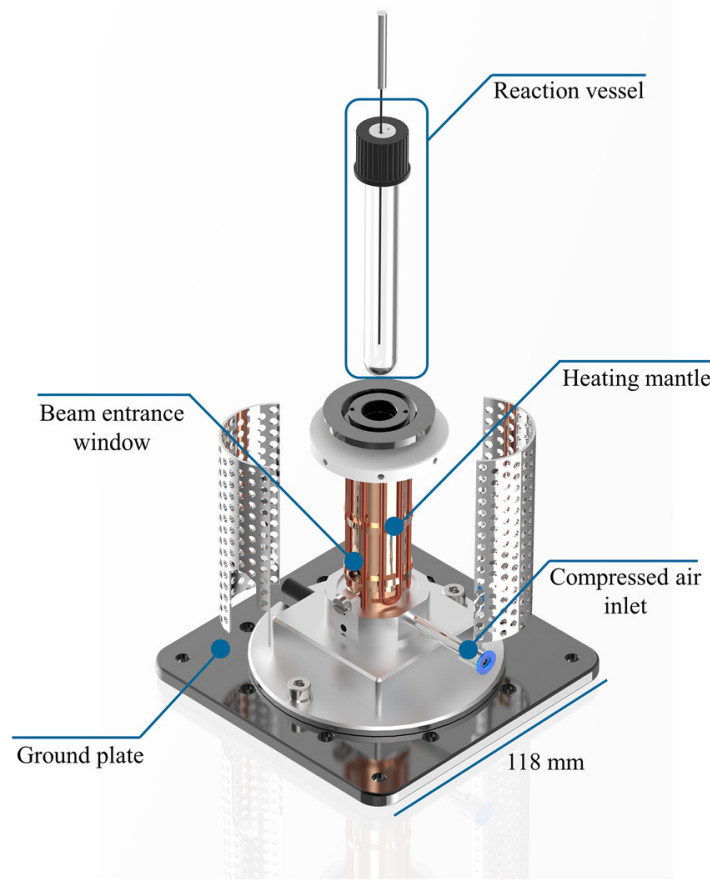

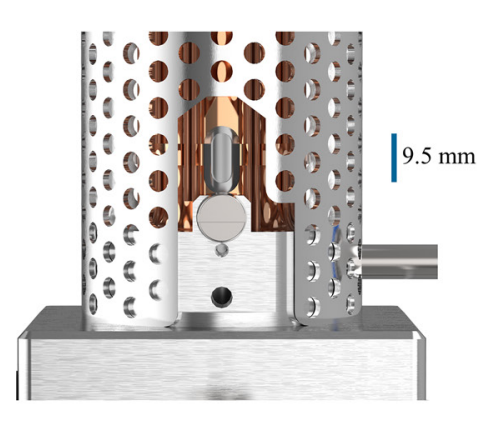

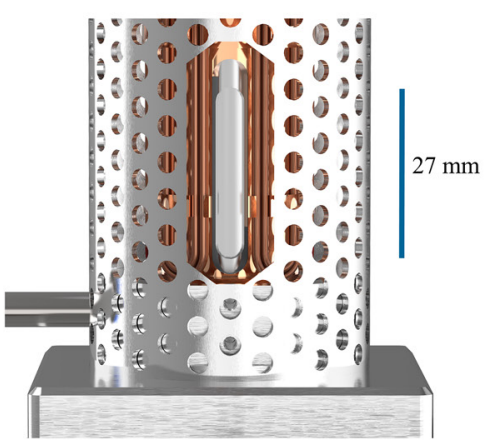

FIG. 2. Schematic of the in situ cell (left) and close-up view of the entrance (top right) and exit (bottom right) windows. temperature, a flow of compressed air is automatically directed onto the heating mantle.

The temperature data are measured at two different points using K-type thermocouples. One thermocouple (Electronic Sensor $\mathrm{GmbH}$ ) is integrated in the heating mantle, while the second thermocouple (Reckmann $\mathrm{GmbH}$ ) is embedded in the glass vessel screw cap and monitors the temperature inside the reaction vessel (Fig. 4). The glass vessel screw cap is made from glass-fiber reinforced polyphenylsulfide (PPS, Bohlender $\mathrm{GmbH}$ ) with a custom-built PTFE inset that seals the cap and holds the thermocouple. To prevent corrosion, the thermocouple is coated with a PTFE/PFA-two-component shrinking tube (Polytetra GmbH, PFA = Perfluoroether). Additionally a second layer of PTFE/PFA-two-component tube is applied right below the PTFE inset. This second layer acts as a restraint to prevent the thermocouple from being pushed out in reactions at high autogenous pressures. The same technique is also used for the injection tubes (Sec. II D).

The data of both K-type thermocouple modules are registered by a compact chassis (National Instruments) and transferred to the connected laptop. A set of proportional-integralderivative (PID) parameters integrated in the reactor operating software controls the heating of the reaction vessel to keep the temperature as close as possible to the specified target value.
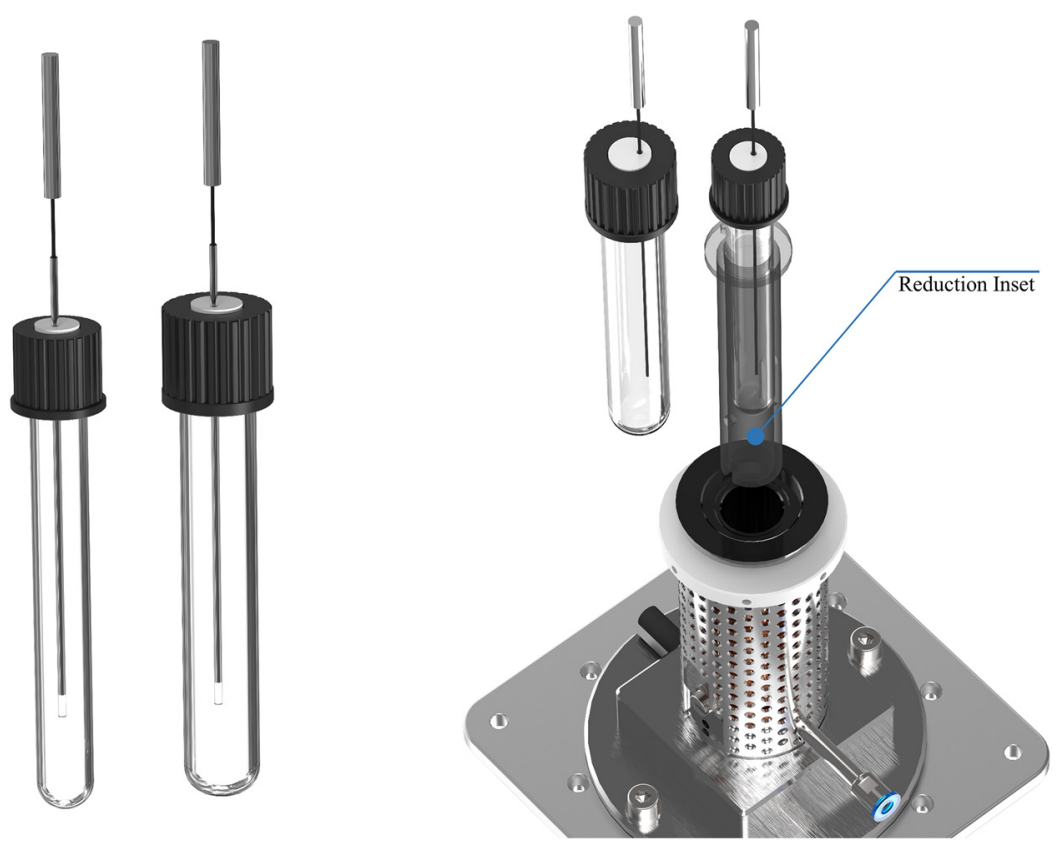

FIG. 3. Schematic of the two sizes of borosilicate glass vessels (left) and top view of the reaction cell with the reduction inset (right, solid aluminum depicted partly transparent) used to change between the two sizes. 


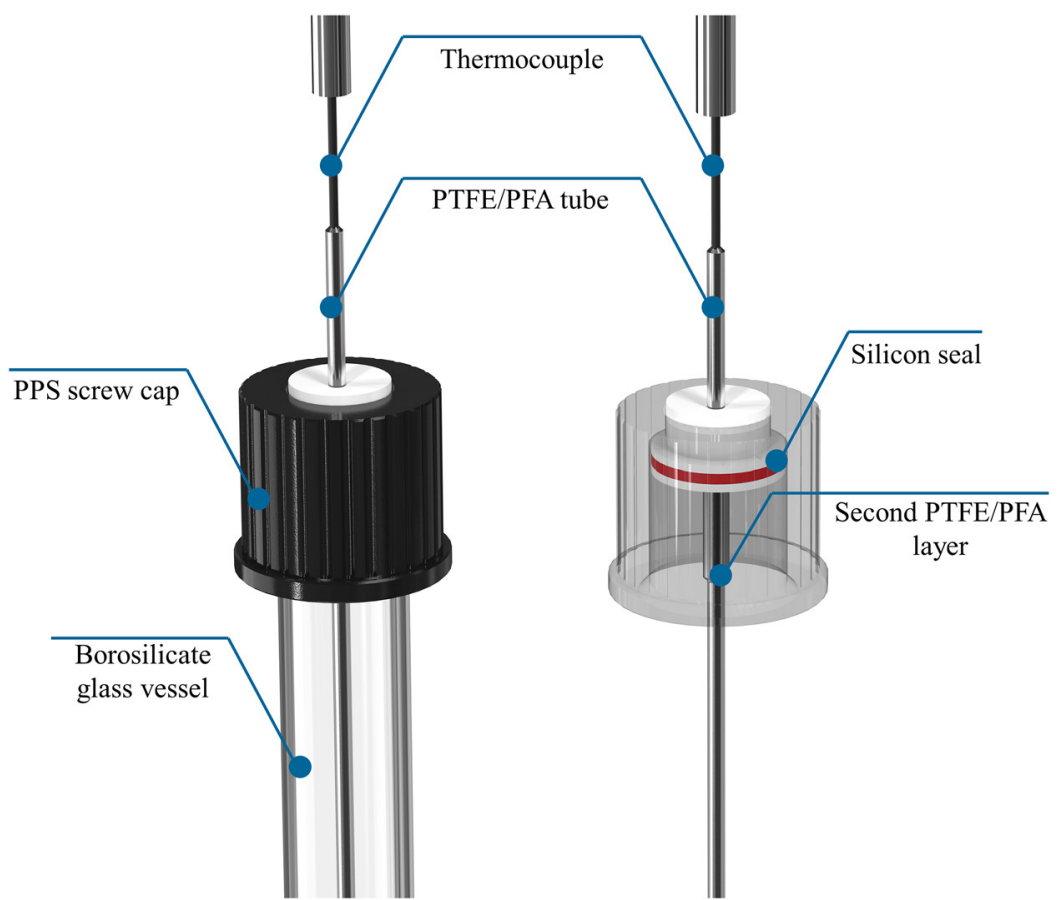

FIG. 4. Schematic view of the screw cap including the PTFE inset that holds the PTFE/PFA-coated thermocouple.

This is accomplished through a combination of pulsed heating and direct cooling of the heating mantle. In the supplementary material (Fig. S2), a heating process to the maximum temperature of $180{ }^{\circ} \mathrm{C}$ is shown for both types of reaction vessels.

\section{Injection system}

One main purpose of the SynRAC reactor setup is the interactive manipulation by adapting temperatures and addition of substances during a chemical reaction and study the response to these altered conditions. To this end, an injection system has been incorporated in the setup. The neMESYS syringe pump system (Fig. 5, Cetoni $\mathrm{GmbH}$ ) can mount up to two syringes. By default, the setup is operated with two $5 \mathrm{ml}$ borosilicate glass syringes (Fig. 5, ILS Microsyringes) that can inject liquids with a flow between $5.7 \mu \mathrm{l} / \mathrm{min}$ and $30 \mathrm{ml} / \mathrm{min}$ while withstanding a backpressure of 17 bars. These syringes are connected to specially designed screw caps (Fig. 5).
The tubes (Erich Eydam KG) embedded in the screw cap are made from PTFE to enable injection of even aggressive or reactive liquid additives.

The syringe pump system is connected to the control laptop via USB connection and controlled by the reactor operating software (Sec. II G).

\section{E. Safety measures}

Chemical reactions under solvothermal conditions always carry the risk of reaction vessel burst due to a high autogenous pressure building up inside the vessel. To avoid any risk to involved personnel or contamination of beamline equipment, SynRAC includes several hardware and software related measures to address these safety issues.

To generally reduce the risk of a glass vessel burst, the reactor is only operated at conditions that are significantly lower than the limit of all the incorporated components. The polyphenylsulfide screw caps, for instance, are stable
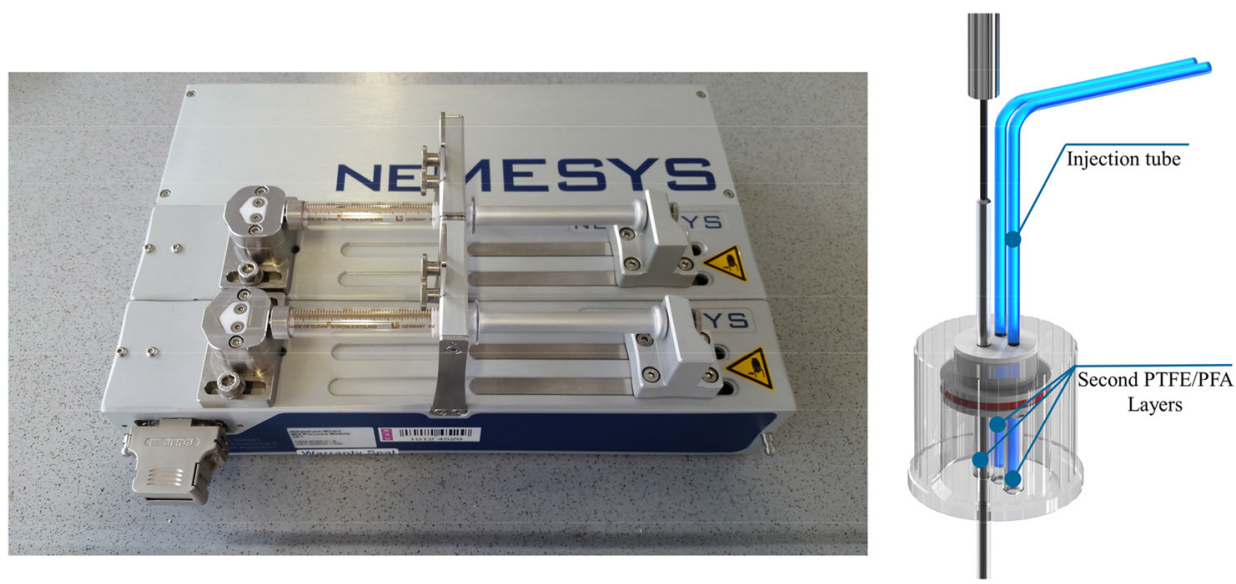

FIG. 5. Syringe pump system neMESYS (left) and custom-built screw cap used for injection of liquids (right, the injection tubes are depicted in blue to increase visibility). 
up to $250{ }^{\circ} \mathrm{C}$ even though the maximum operating temperature of the cell currently lies at $180{ }^{\circ} \mathrm{C}$. Should a glass vessel burst occur despite these precautions, the reactor cell is equipped with thinned out aluminum windows to contain any leaked chemicals. In addition to the windows, a safety cap made from aluminum (Fig. S3 of the supplementary material) can be mounted onto the setup. With the safety cap in place, no chemicals that get ejected in the case of a burst can spill out of the setup, protecting the users as well as the beamline equipment from injury or contamination, respectively.

The operating software is outfitted with an electronic safety limit that restricts the temperature of the heating mantle to a value below $200{ }^{\circ} \mathrm{C}$, effectively leading to a maximum temperature of $180{ }^{\circ} \mathrm{C}$ inside the reaction vessel. Should the laptop, for example, lose the connection to the reactor setup due to network issues, the heating mantle still cannot exceed a temperature of $200^{\circ} \mathrm{C}$.

Finally the user operating the reactor provides an additional layer of safety. All the information regarding temperature data and syringe levels is transferred to the user interface in real-time. In the case of critical situations, the user can always intervene and cool down the setup remotely from the control hutch.

\section{F. Solid dosing device}

Even though the injection system already offers great flexibility regarding different experiments, in some cases it might be necessary to add solids. To address these issues, we incorporated, complementary to our liquid injection device, a solid dosing system into our reactor setup. In this section, the solid dosing device is described in detail followed by a proof of concept experiment that was conducted using the solid dosing system at beamline P08.

The solid dosing device consists of a PEEK cylinder embedded in a Teflon inlet as a part of the reaction vessel screw cap (Fig. 6). Due to size restraints, the solid dosing device is however only available for the bigger reaction vessels $\left(\mathrm{V}_{\max }=11 \mathrm{ml}\right)$. Before the experiment, the cylinder is filled with the solid and afterwards sealed with a small Teflon plug to limit the contact between solid and solvent vapor in the reaction vessel. A piston made from PEEK, inserted into the top of the cylinder, is used to push out the solid. The piston is connected to a linear actuator. The whole apparatus is centered on a modified custom-made safety cap to provide stability and address safety issues simultaneously (Fig. S4 of the supplementary material).

When the command to add the solid is issued, the motor actuates the threaded spindle and consequently pushes the slide that is connected to the PEEK-piston down. When the slide reaches the lower end-position switch, the motor reverses the spinning direction and pulls the slide back to its initial position. The solid dosing device was integrated in our reactor operating software and works analogs to our injection system.

To test the capabilities of the solid dosing system, it was tested in the synthesis of a new zirconium and ceriumbased mixed-metal-organic framework (Fig. 7) containing
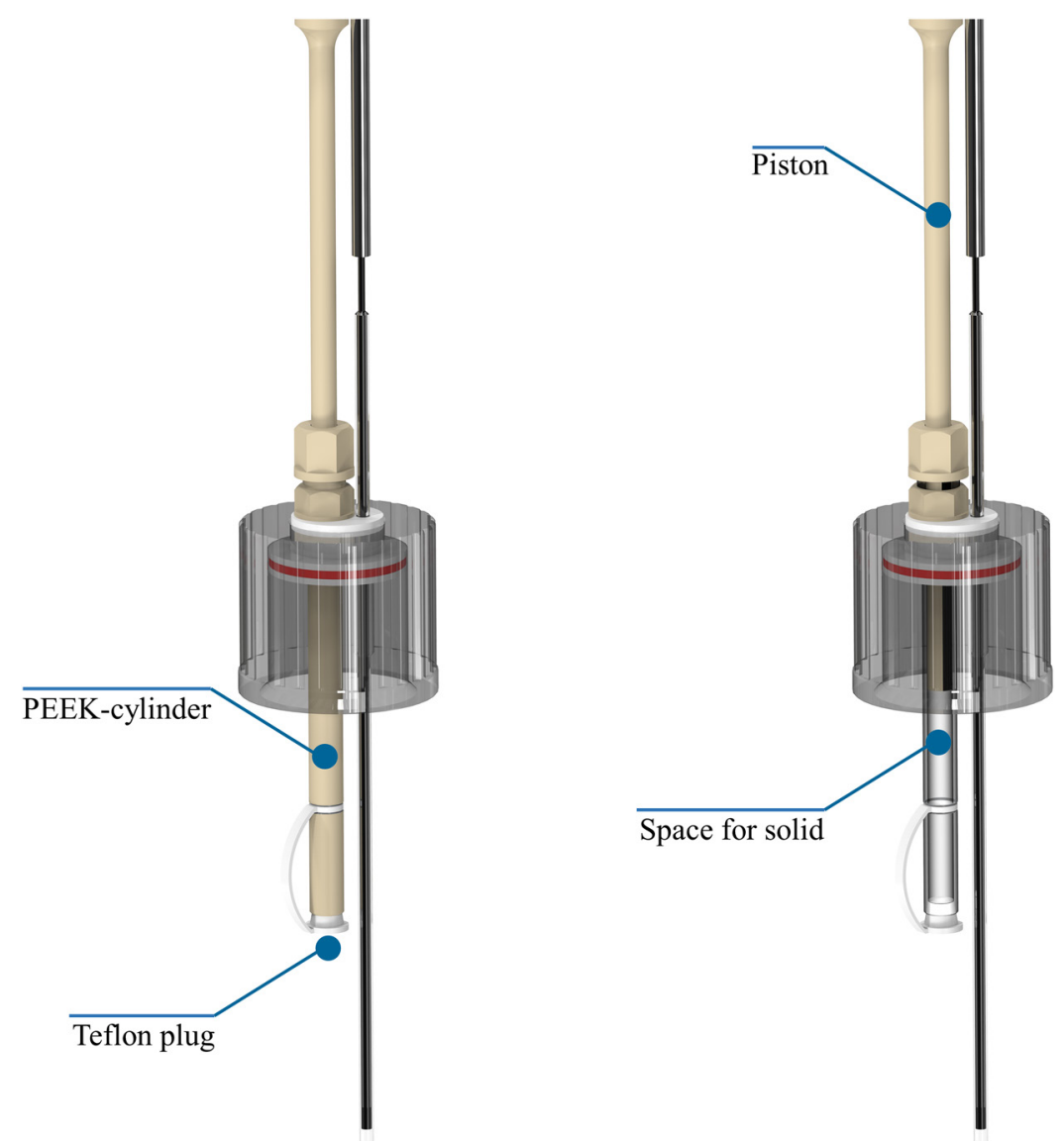

FIG. 6. Schematic view of the modified screw cap used for solid dosing. On the right, the PEEK cylinder is depicted transparent to clarify the available space for the solid. 

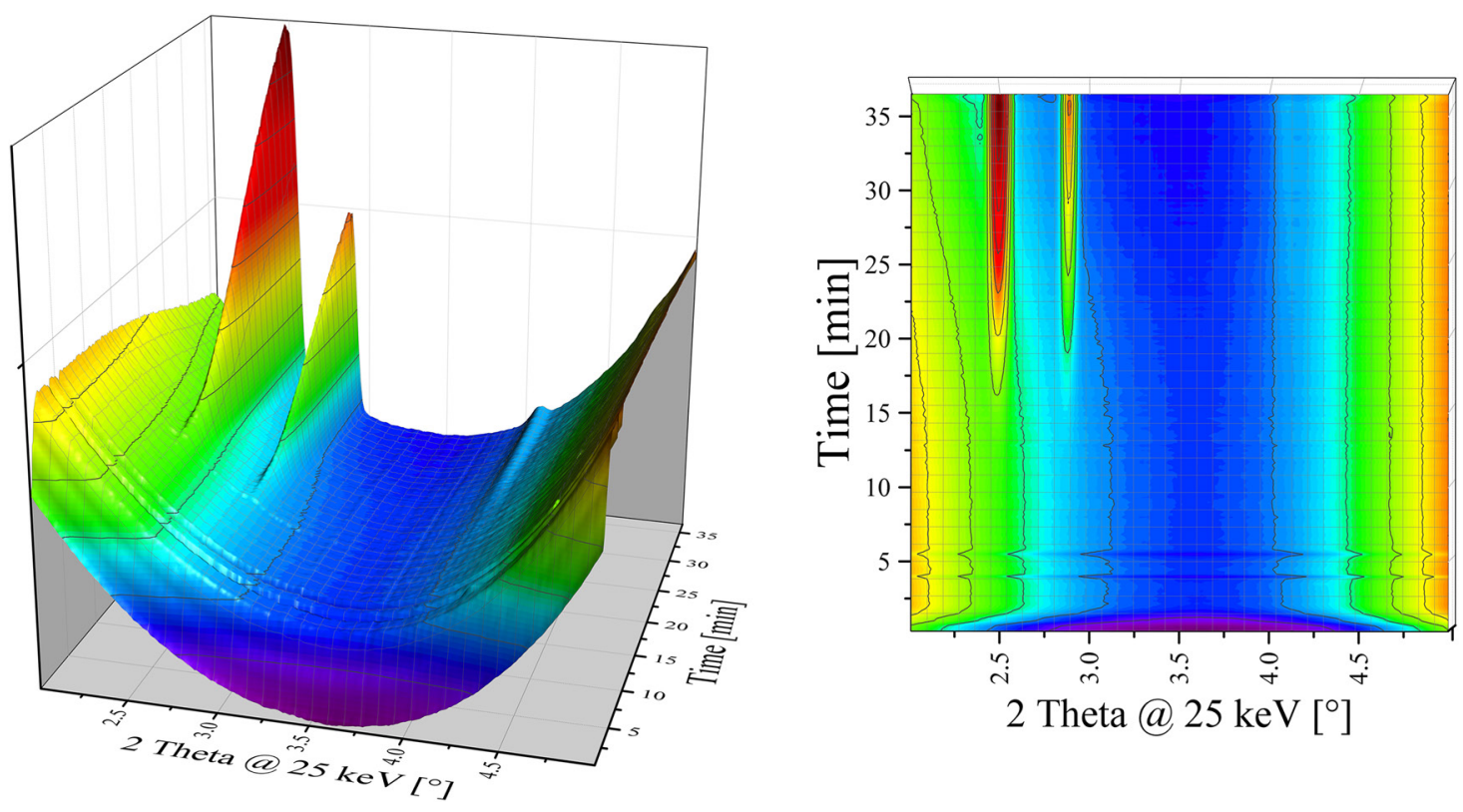

FIG. 7. 3D (left) and flat (right) representation of the diffraction data obtained in the synthesis of a cerium/zirconium mixed metal MOF using the solid dosing system.

pyrazoledicarboxylic acid $\left(\mathrm{H}_{2} \mathrm{Pzdc}\right)$ with the sum formula $\left[\mathrm{CeZr}_{5}\left(\mu_{3}-\mathrm{O}\right)_{4}\left(\mu_{3}-\mathrm{OH}\right)_{4}(\mathrm{Pzdc})_{4}(\mathrm{OH})_{4}\left(\mathrm{H}_{2} \mathrm{O}\right)_{4}\right]$.

\section{Materials}

All used chemicals are commercially available and were used without further purification.

\section{Methods}

Before the reaction, two solutions of zirconiumoxynitrate in $\mathrm{H}_{2} \mathrm{O}(0.5333 \mathrm{M})$ and cerium ammonium nitrate $(\mathrm{CAN})$ in $\mathrm{H}_{2} \mathrm{O}(0.5333 \mathrm{M})$ were prepared. Of these solutions, $480 \mu \mathrm{l}$ zirconiumoxynitrate solution and $120 \mu \mathrm{l} \mathrm{CAN-solution} \mathrm{were}$ transferred to a $11 \mathrm{ml}$ borosilicate vessel containing $1200 \mu \mathrm{l}$ DMF and $2113.5 \mu \mathrm{l}$ formic acid. The solid dosing system was filled with $83.55 \mathrm{mg}$ pyrazoledicarboxylic acid $\left(\mathrm{H}_{2} \mathrm{Pzdc}\right)$. The reaction mixture was heated to the target temperature of 100 ${ }^{\circ} \mathrm{C}$ and kept under continuous stirring during the whole experiment. After $3.5 \mathrm{~min}$ into the experiment, the linker was added using the solid dosing system. The diffraction patterns were collected at beamline P08, PETRA III, DESY. Diffraction data were measured using a monochromated radiation of $25 \mathrm{keV}$ $(\lambda=0.49590 \AA)$ with a beam size of $0.5 \mathrm{~mm} \times 0.5 \mathrm{~mm}$. The 2D images were collected on a Perkin Elmer XRD1621 flat panel detector $(2048 \times 2048$ pixel, $200 \times 200 \mu \mathrm{m}$ pixel size) with a time resolution of $10 \mathrm{~s}$ per image. The images were integrated with the FIT2D software package. The exact sample-to-detector distance was calculated as $644.7 \mathrm{~mm}$.

At the start of the experiment, only the diffuse background scattering corresponding to glass and solution inside the reaction vessel is visible. As the temperature inside the reaction vessel rises to the target temperature of $100{ }^{\circ} \mathrm{C}$, the intensity of the background increases until it reaches a stable level. At about $3.5 \mathrm{~min}$ into the experiment, the solid dosing step was initiated and the linker was pushed into the reaction vessel. At the point of addition, a very slight decrease in temperature is visible that is mostly noticeable in the rising temperature of the heating mantle to compensate for the lower inside-vial temperature (Fig. 8).

After $\sim 17$ min into the experiment, crystallization of the compound starts, verifying that the linker was successfully added to the reaction mixture.

\section{G. Reactor operation}

The reactor setup SynRAC is operated with a customprogrammed software based on LabView. The software provides a user interface that combines all the relevant information like temperature data and syringe fill levels, displays them in real-time, and stores them for later assessment. The software can easily be installed on any laptop and works as a standalone

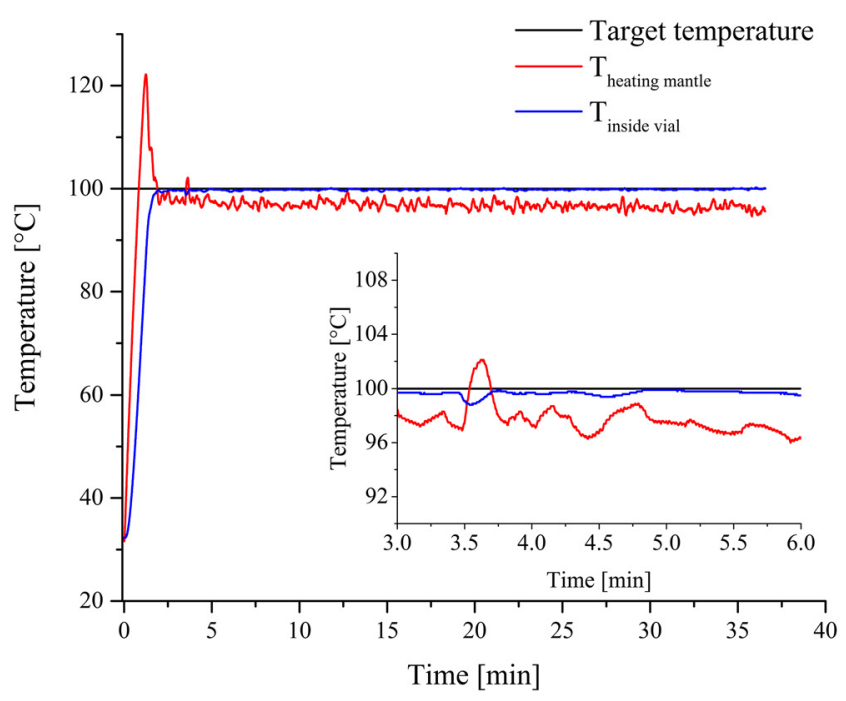

FIG. 8. Temperature data associated with the synthesis of a cerium/zirconium mixed-metal MOF using the solid dosing device at beamline P08. 
system. This way the reactor program is independent from any beamline equipment and can be used at every beamline. Before an experiment, a procedure of actions like heating, injection, or waiting steps is defined. When the experiment starts, the software will execute these steps in the specified order. In the case of unforeseen events, the user can always intervene and, for example, skip a step to immediately quench a reaction via injection of solvent or modify the program in any other way.

\section{H. Calibration and alignment}

At the start of an investigation at a synchrotron, especially the alignment of the reaction cell can be a tedious and time-consuming task. Additionally several characterization techniques require an accurate determination of the distance between the sample and detector. In the case of X-ray diffraction (XRD), this is accomplished by collecting the powder pattern of a well-known standard substance (e.g., $\mathrm{LaB}_{6}$ ) and using the position of the reflections on the detector in combination with the accurate wavelength to calculate the exact sample-to-detector distance.

In the design of SynRAC, ease of use was an important aspect. Therefore tasks like reactor alignment and distance measurement were facilitated to be as simple as possible. For that purpose, a calibration inset (Fig. 9) made from copper was constructed that can be inserted into the cell. The inset can accommodate a holder containing a capillary filled with a standard substance (e.g., $\mathrm{LaB}_{6}$ ). The capillary holders are available at PETRA III at various beamlines. The inset possesses openings in the region where the beam entrance and exit windows in the reactor cell are located. The copper holder with small openings of the capillary simplifies the very precise alignment of the capillary in the beam. When moving the reactor by means of an xyz table, the copper reflections corresponding to the calibration inset will be visible as long as the beam is not passing exactly through the beam windows of the cell. Once the correct reactor position is found, the reflections corresponding to copper will vanish and only the ones of the

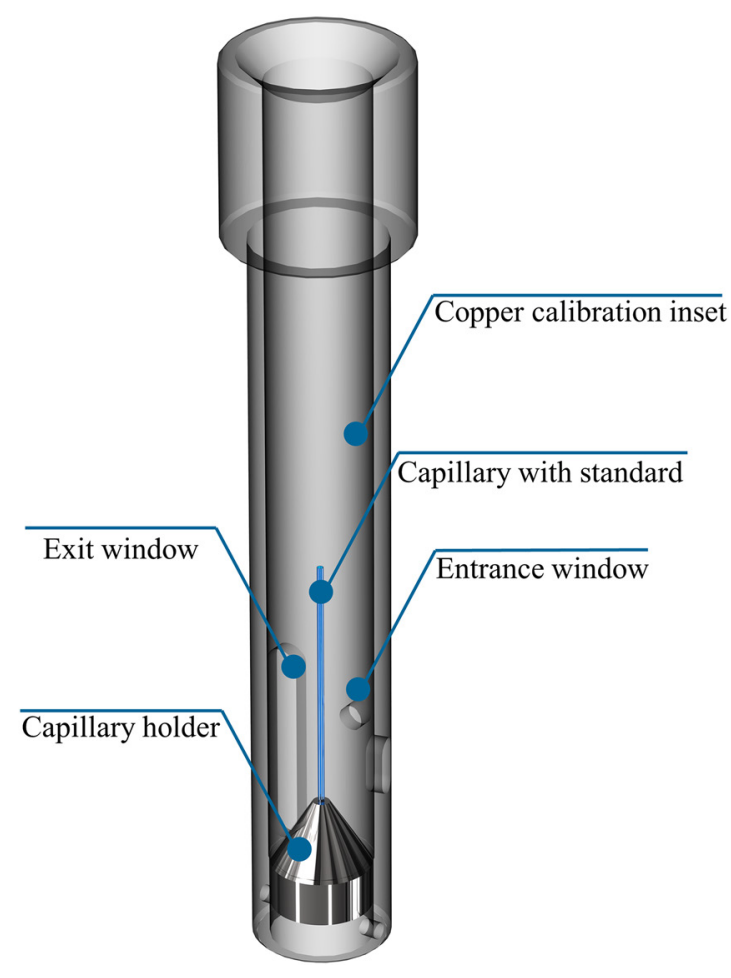

FIG. 9. Calibration inset with standard capillary (solid copper is depicted transparent to increase visibility).

standard substance in addition to the ones of the aluminum windows will be visible.

After the cell has been properly aligned in the beam, several diffraction patterns can be collected that can afterwards be used for the distance calibration of the sample and detector and as a reference for the experimental resolution.

\section{Data treatment}

In an in situ experiment using X-ray diffraction, the overall intensity between consecutive patterns can potentially
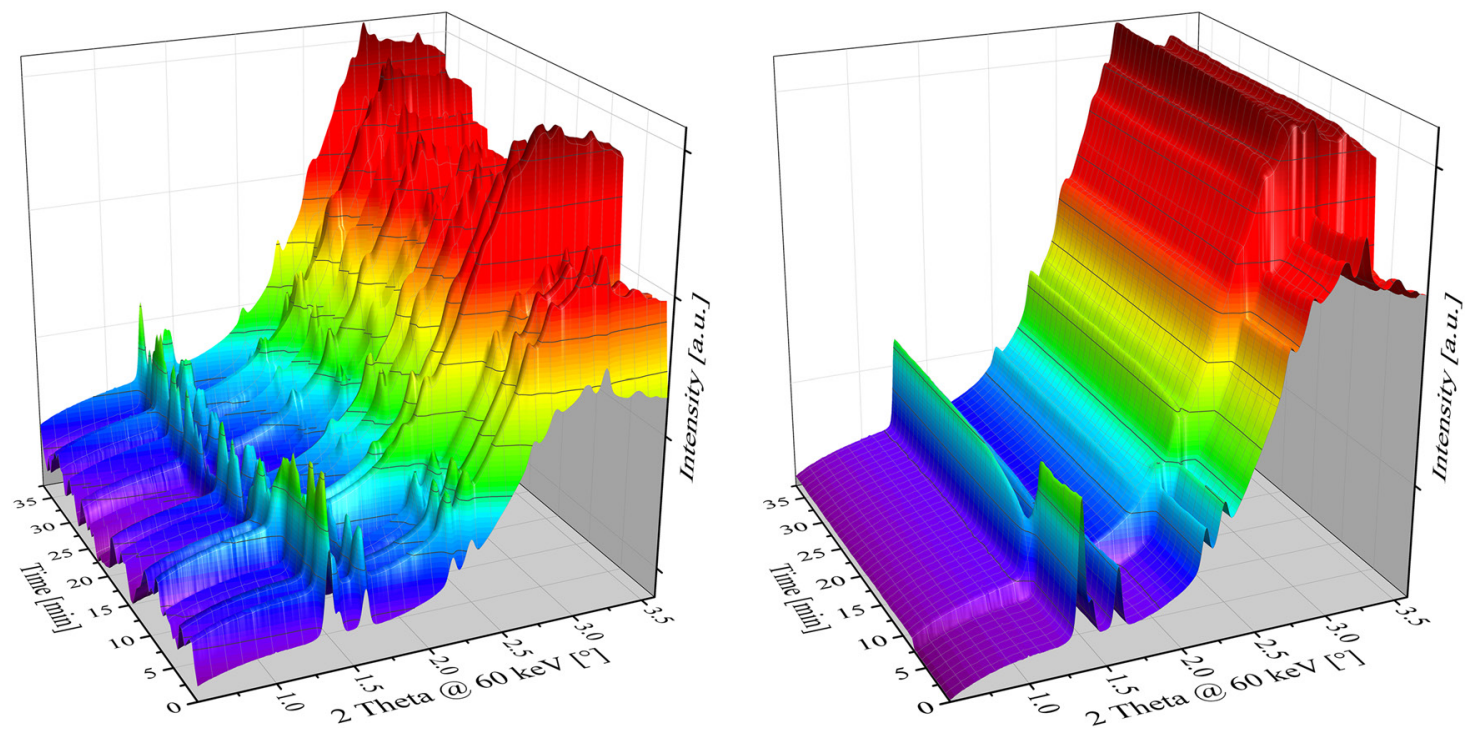

FIG. 10. Same set of diffraction patterns before (left) and after (right) normalization to the 311 Bragg reflection of the exit-window. ${ }^{27}$ 
differ significantly. There are several effects contributing to these intensity fluctuations like variation due to the stability of beamline optics or even due to the current in the storage ring. However the biggest contribution in the case of in situ experiments probably comes from changing spatial distributions of particles inside the reaction vessel. Stirring certainly improves the quality but despite stirring there might be different amounts of solids in the beam from one pattern compared to the previous one. Consequently this leads to a varying total absorption of the sample resulting in an overall lower or higher pattern intensity, respectively. Especially in reactions where the main interest is the crystallization kinetics of a compound, these fluctuations can be detrimental for data evaluation. In these cases, it can prove helpful to include a standard inside the reaction mixture that shows the same fluctuations. As the intensity of the reflections corresponding to the standard should remain constant during the reaction, it can be used to normalize all the patterns provided the standard exhibits the same local inhomogeneities as the reaction product. In chemical reactions, an internal standard could be problematic as it might take part in a reaction. Hence in SynRAC, the aluminum windows are used as an external standard.

In Fig. 10, two series of diffraction patterns that were obtained at beamline $\mathrm{P} 02.1$ associated with the intercalation of pyrazine in $\left[\mathrm{Al}(\mathrm{OH})\left(\mathrm{O}_{2} \mathrm{C}-\mathrm{C}_{6} \mathrm{H}_{10}-\mathrm{CO}_{2}\right)\right] \cdot \mathrm{H}_{2} \mathrm{O}(\mathrm{CAU}-13)$ are shown. ${ }^{27}$ The left picture shows an untreated series of diffraction patterns that exhibit strong intensity variations between consecutive patterns. The right picture shows the same dataset after normalizing all patterns to the same intensity for the 311 Bragg reflection of the exit window. The significant jump in the background at $\mathrm{t}=7.5 \mathrm{~min}$ corresponds to an injection step of a pyrazine solution.

\section{CASE STUDIES}

Coordination polymers are crystalline compounds composed of inorganic building units that are bridged by organic linkers to form networks. Among the group of coordination polymers, metal-organic frameworks (MOFs) represent a class of porous materials that crystallize in 2- or 3-dimensional networks and exhibit the highest specific surface areas known today paired with a very narrow pore size distribution due to their crystalline nature. The combination of these properties makes them well suited for various applications ranging from catalysis over drug delivery to heat transformation as well as applications in gas storage and separation. Consequently MOFs experienced a growing interest in research and were subjected to a variety of different in situ studies to, for instance, clarify the mechanisms behind their crystallization ${ }^{3,5}$ or to analyze phase transformations. In Sec. III A, two examples of studies that were conducted using the in situ setup are briefly described. In the experiments that were carried out in SynRAC so far, the focus mostly lay on XRD studies to analyze crystallization kinetics, phase transformations, or the formation of intermediate phases during the synthesis of coordination polymers or metal-organic frameworks. ${ }^{27-29}$ However, the reactor has recently been applied in the field of combined X-ray absorption spectroscopy (XAS) and Xray diffraction (XRD) analysis. In this multimodal approach, the catalysis of $\mathrm{C}-\mathrm{C}$-coupling reactions in the presence of MOFs decorated with palladium nanoparticles as catalyst was investigated. ${ }^{30}$

\section{A. Crystallization kinetics of Ce-UiO-66}

Among metal-organic frameworks, zirconium-based UiO- $66^{31}$ (UiO = University of Oslo) is one of the most extensively studied compounds due to its significant thermal and chemical stability compared to other MOFs. Recently we have reported the synthesis of Ce-MOFs and their use in catalysis. $^{32,33}$ The aim of this experiment was to analyze the crystallization kinetics of the compound denoted Ce-UiO-66 $\left[\mathrm{Ce}_{6}(\mathrm{OH})_{4}(\mathrm{O})_{4}(\mathrm{BDC})_{6}\right]$. The metal-organic framework crystallizes in a rapid reaction between cerium ammonium nitrate $\left[\left(\mathrm{NH}_{4}\right)_{2}\left[\mathrm{Ce}\left(\mathrm{NO}_{3}\right)_{6}\right]\right]$ and terephthalic acid $\left(\mathrm{H}_{2} \mathrm{BDC}\right)$ in a solvent mixture of $\mathrm{N}, \mathrm{N}$-dimethylformamide (DMF) and $\mathrm{H}_{2} \mathrm{O}$ (Fig. 11).

The analysis of the crystallization kinetics of this reaction proved challenging as the first reflections already appear

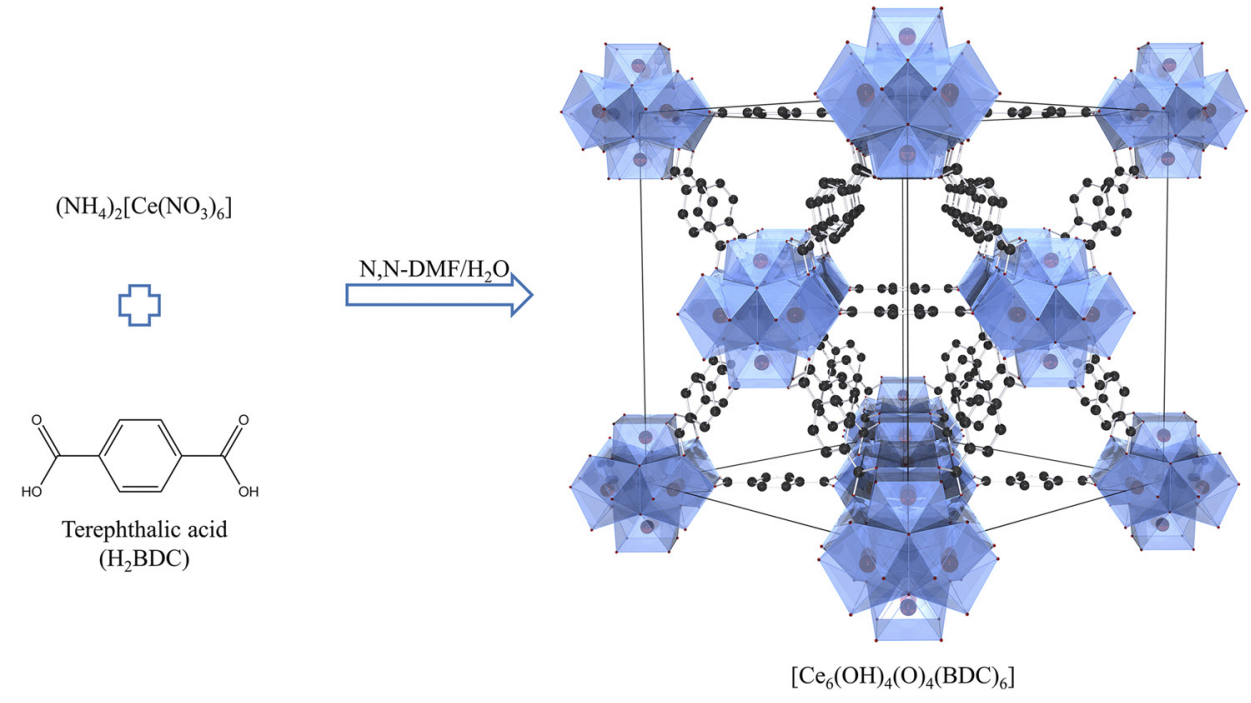

FIG. 11. Reaction of cerium ammonium nitrate and terephthalic acid to Ce-UiO-66. 


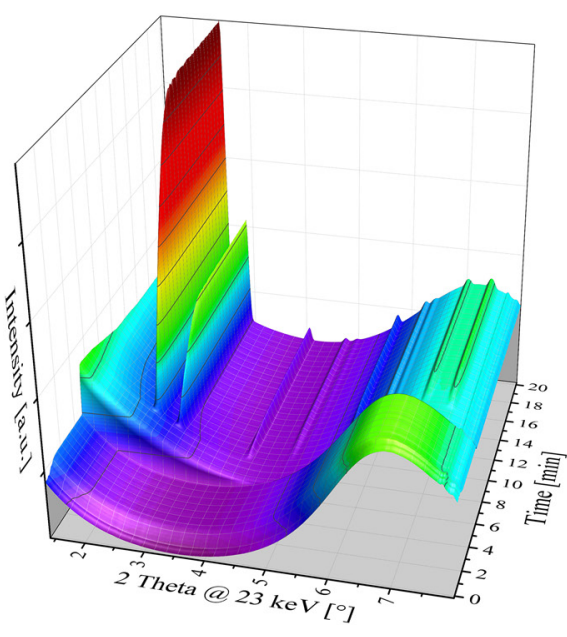

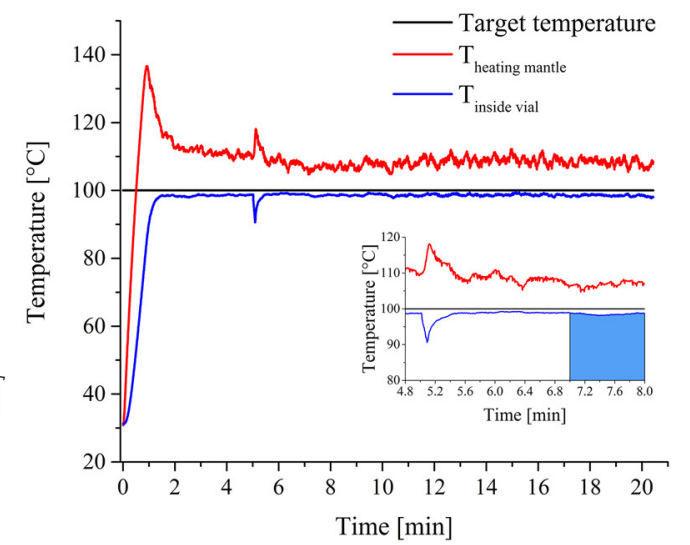

FIG. 12. XRD data corresponding to the synthesis of Ce-UiO-66 (left) at $100{ }^{\circ} \mathrm{C}$ and the associated temperature data (right, the blue region marks the time where the first reflection appears). after $\sim 1.5$ min reaction time. In order to determine the kinetics of a crystallization process, the temperature should be stable throughout the whole reaction to exclude any influence of the heating rate on the formation kinetics. To address this challenge, the solvent/linker-solution was initially heated to the target temperature followed by the addition of the metal salt solution via injection.

\section{Materials}

All used chemicals are commercially available and were used without further purification.

\section{Methods}

A solution of $70 \mathrm{mg}$ terephthalic acid $(0.42 \mathrm{mmol})$ in $2.4 \mathrm{ml} \mathrm{DMF}$ was placed in a $5 \mathrm{ml}$ borosilicate vessel and heated to different target temperatures of $100{ }^{\circ} \mathrm{C}, 90{ }^{\circ} \mathrm{C}, 80{ }^{\circ} \mathrm{C}$, and $70{ }^{\circ} \mathrm{C}$ under stirring. After $5 \mathrm{~min}, 800 \mu \mathrm{l}$ of a $0.53 \mathrm{M}$ aqueous solution of $\left(\mathrm{NH}_{4}\right)_{2}\left[\mathrm{Ce}\left(\mathrm{NO}_{3}\right)_{6}\right]$ was added via injection. The diffraction patterns were collected at beamline P09, ${ }^{34}$ PETRA III at DESY. Diffraction data were measured using monochromated radiation $(23 \mathrm{keV}, \lambda=0.53905 \AA$ ) with a beam size of $1 \mathrm{~mm} \times 1 \mathrm{~mm}$. The $2 \mathrm{D}$ images were acquired with a time resolution of $5 \mathrm{~s}$ per frame on a Perkin Elmer XRD1621 flat panel detector $(2048 \times 2048$ pixel; $200 \times 200 \mu$ m pixel size $)$ and integrated with the Fit2 $\mathrm{D}^{35}$ software package. The exact sample-to-detector distance was calculated as $606.1 \mathrm{~mm}$.

At the beginning of the experiment, the organic linker solution was heated to different target temperatures of $100{ }^{\circ} \mathrm{C}$, $90{ }^{\circ} \mathrm{C}, 80^{\circ} \mathrm{C}$, and $70{ }^{\circ} \mathrm{C}$. Since the crystallization occurred from solution, initially no Bragg reflections were visible alongside the diffuse scattering around $\sim 6.5^{\circ} 2$ Theta that can be attributed to the solvent and glass vessel. At $\mathrm{t}=5 \mathrm{~min}$, the cerium salt solution was injected leading to a decrease in overall intensity due to the higher absorption by the sample. As evident in the temperature data (Fig. 12, right), the reactor program immediately started to compensate for the lower temperature inside the reaction vessel with a raised mantle temperature. Roughly 20 s after the injection step, the temperature reached the target temperature again and stayed at $100{ }^{\circ} \mathrm{C}$ with a deviation of $\sim \pm 0.6^{\circ} \mathrm{C}$. The reflections corresponding to the MOF appeared $\sim 2$ min after the injection of the metal salt solution. As the temperature inside the reaction vessel was stable at the target temperature, at that point the crystallization kinetics can be considered independent from any change in temperature.

As a measure of the reaction progress $\alpha$, the area under the 111 Bragg reflection of $\mathrm{Ce}-\mathrm{UiO}-66$ was integrated with the software package "F3tool" and plotted against the experiment time (Fig. 13). To evaluate the kinetic parameters for each reaction, the reaction progress was fitted with a non-linear curve fit based on the Gualtieri model ${ }^{36}$ [Eq. (1)],

$$
\alpha=\frac{1}{1+\exp \left[-\left(\frac{\mathrm{t}-\mathrm{a}}{\mathrm{b}}\right)\right]}\left[1-\exp \left(\mathrm{k}_{\mathrm{g}} \mathrm{t}\right)^{\mathrm{n}}\right] .
$$

According to the Gualtieri model, the reaction progress $\alpha$ is expressed as a function of reaction time $t$ and the parameters $a=k_{n}{ }^{-1}\left(k_{n}=\right.$ rate constant of nucleation), $b, k_{g}\left(k_{g}=\right.$ rate constant of crystal growth), and $n$ (dimension of growth).

The particles forming in this reaction exhibit cube-shaped morphology indicating a three-dimensional growth in the course of the reaction. Accordingly, $n$ was defined as 3 for this

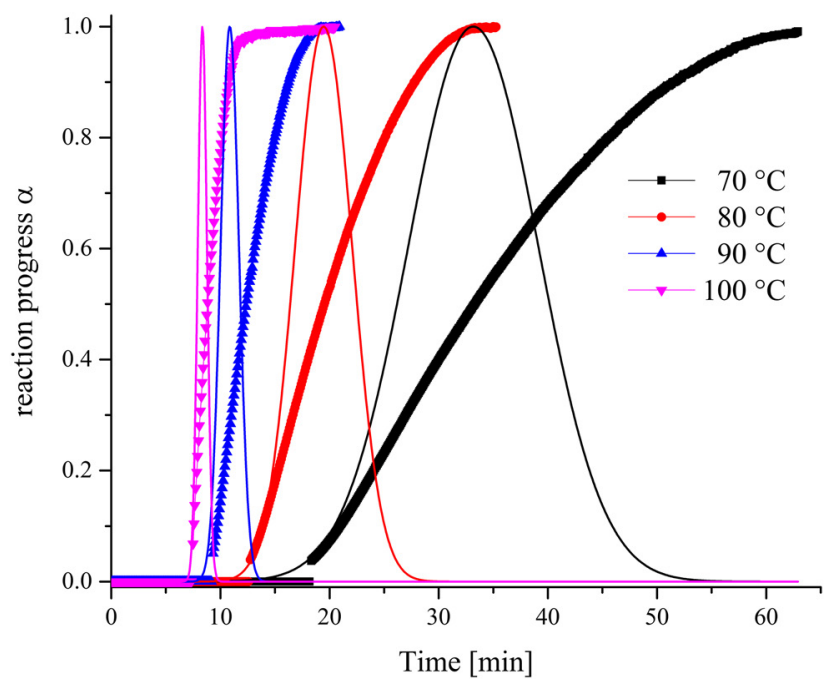

FIG. 13. Reaction progress $(\alpha)$ and nucleation probability $\left(\mathrm{P}_{\mathrm{n}}\right)$ plotted against the experiment time (t) for the synthesis of Ce-UiO-66 at four different temperatures. 
experiment. The probability of nucleation $\mathrm{P}_{\mathrm{n}}$ was calculated from the following equation based on the parameters derived from the Gualtieri fit:

$$
P_{n}=e^{\frac{-(t-a)^{2}}{b^{2}}}
$$

The Arrhenius activation energies for nucleation and crystal growth were determined by plotting $\ln (\mathrm{k})$ against $1 / \mathrm{T}$ (Fig. S5 of the supplementary material). The activation energies were calculated as $32(5) \mathrm{kJ} / \mathrm{mol}$ for crystal growth and $50(5) \mathrm{kJ} / \mathrm{mol}$ for nucleation, respectively. The calculated values lie slightly below the values of activation energies reported for other metal-organic frameworks in the literature (Mn-MIL$100:^{37}$ 89.9-126.5 kJ/mol; MOF-14: ${ }^{13}$ 64-83 kJ/mol; CAU$13:^{38} 76-77 \mathrm{~kJ} / \mathrm{mol}$; and CAU-1: ${ }^{39} 131-136 \mathrm{~kJ} / \mathrm{mol}$ ). This is however reasonable as the reaction occurs at mild reaction conditions compared to the other compounds. In this case, crystallization occurs very fast at reaction temperatures well below the boiling point of the employed solvent mixture indicating a comparably low activation energy.

\section{B. Isolation of short lived intermediates-Basic bis- muth nitrate}

In the synthesis of porous crystalline materials, the product formation often progresses via amorphous or crystalline intermediate phases. Understanding the structural relationship between the intermediate and product phases can provide information about the reaction mechanism which can subsequently lead to a more efficient reaction process. In ex situ experiments, short lived intermediate phases can be missed easily. Moreover there is no guarantee that the isolation and washing steps will not alter the structure of the intermediate phase consequently falsifying any conclusions that can be drawn about the reaction mechanism. In such cases, it can be a viable strategy to isolate these intermediate phases directly at the beamline as soon as they are observed. Due to the large contribution of the solvent background that overlays a lot of smaller product reflections, in situ data are usually not suitable for a structure determination. After isolation, however the intermediate phase can be analyzed with high-resolution diffraction methods provided it stayed intact during the isolation process. In Sec. III B 1, one example of the isolation of a short-lived intermediate using the SynRAC setup is briefly presented.

In this second example, the formation of a bismuth-based coordination polymer denoted $[\mathrm{Bi}(\mathrm{HIDC})(\mathrm{IDC})]^{40}$ was analyzed with $\mathrm{X}$-ray powder diffraction. The coordination polymer forms in the reaction of bismuth nitrate $\left[\mathrm{Bi}\left(\mathrm{NO}_{3}\right)_{3}\right]$ with 4,5-imidazoledicarboxylic acid $\left(\mathrm{H}_{2} \mathrm{IDC}\right)$ in $\mathrm{H}_{2} \mathrm{O}$. Bismuthbased compounds are generally interesting candidates to study reaction mechanisms as their formation often progresses via crystalline intermediate phases. ${ }^{41}$ A reason for this might lie in the large structural diversity of inorganic building units found in bismuth-based MOFs and coordination polymers.

\section{Materials}

All used chemicals are commercially available and were used without further purification.

\section{Methods}

In this reaction, $80 \mathrm{mg} \mathrm{Bi}\left(\mathrm{NO}_{3}\right)_{3} \cdot 5 \mathrm{H}_{2} \mathrm{O}(0.16 \mathrm{mmol})$ and $52 \mathrm{mg}(0.333 \mathrm{mmol})$ 4,5-imidazoledicarboxylic acid $\left(\mathrm{H}_{2} \mathrm{IDC}\right)$ were placed in a $5 \mathrm{ml}$ borosilicate vessel followed by $3 \mathrm{ml}$ deionized $\mathrm{H}_{2} \mathrm{O}$. The reaction mixture was heated to $140{ }^{\circ} \mathrm{C}$ within $143 \mathrm{~s}$ under stirring. The diffraction patterns were collected at beamline P09, PETRA III at DESY. Diffraction data were measured using monochromated radiation $(23 \mathrm{keV}$, $\lambda=0.53905 \AA$ ) with a beam size of $1 \mathrm{~mm} \times 1 \mathrm{~mm}$. The $2 \mathrm{D}$ images were acquired with a time resolution of $5 \mathrm{~s}$ per frame on a Perkin Elmer XRD1621 flat panel detector $(2048 \times 2048$ pixel; $200 \times 200 \mu \mathrm{m}$ pixel size) and integrated with the Fit2D software package. The exact sample-to-detector distance was calculated as $606.1 \mathrm{~mm}$. The time-resolved series of X-ray diffraction patterns is shown in Fig. 14.

In the beginning of the experiment, only the reflections corresponding to the reactants $\mathrm{Bi}\left(\mathrm{NO}_{3}\right)_{3}$ and $\mathrm{H}_{2}$ IDC were visible followed by a phase transformation at $\mathrm{t}=1 \mathrm{~min}$. The phase transformation appeared to only involve $\mathrm{Bi}\left(\mathrm{NO}_{3}\right)_{3}$ as the reflections belonging to the organic linker remained unaffected (Fig. S6 of the supplementary material). Additionally a rise of scattering signal in the small angle region was observed, indicating the presence of small particles inside the reaction mixture. The intermediate phase remained intact for a brief time of about $\sim 3 \mathrm{~min}$ followed by the formation of the product
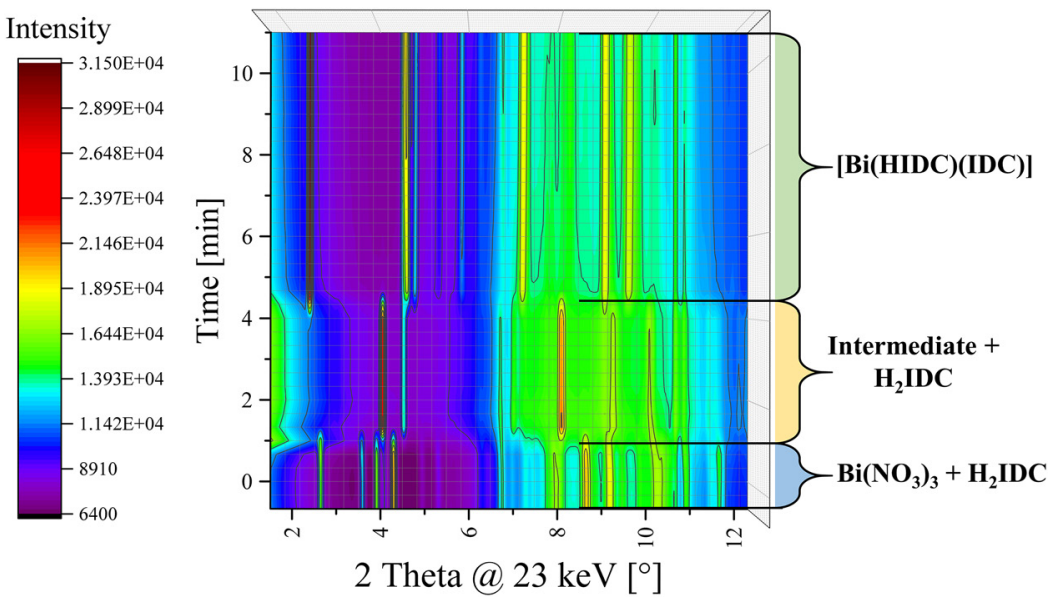

FIG. 14. Flat representation of the XRD data corresponding to the reaction of bismuth nitrate and 4,5-imidazole dicarboxylic acid. The region before $\mathrm{t}=0 \mathrm{~min}$ corresponds to XRD data acquired before heating was initiated. Intermediate $=\left[\mathrm{Bi}_{6} \mathrm{O}_{4}(\mathrm{OH})_{4}\right]_{0.54(1)}\left[\mathrm{Bi}_{6} \mathrm{O}_{5}(\mathrm{OH})_{3}\right]_{0.46(1)}\left(\mathrm{NO}_{3}\right)_{5.54(1)} \cdot{ }^{42}$ 
$[\mathrm{Bi}(\mathrm{HIDC})(\mathrm{IDC})]$ at $\mathrm{t}=4.5 \mathrm{~min}$. To isolate and later identify the intermediate phase, the reaction was repeated starting at $60{ }^{\circ} \mathrm{C}$, increasing the lifetime of the intermediate and delaying the formation of [Bi(HIDC)(IDC)]. In this second experiment, the temperature was step-wise increased from $60{ }^{\circ} \mathrm{C}$ to $80^{\circ} \mathrm{C}$ until the intermediate phase appeared. Once the intermediate had formed, the temperature inside the glass vessel was cooled down from $80{ }^{\circ} \mathrm{C}$ to $40{ }^{\circ} \mathrm{C}$ in $\sim 4 \mathrm{~min}$ (Fig. S7 of the supplementary material) while continuously acquiring XRD data to ensure the structure was retained during the cooling process. After a high-resolution in-house measurement, the intermediate phase was identified as the highly disordered basic bismuth nitrate $\left[\mathrm{Bi}_{6} \mathrm{O}_{4}(\mathrm{OH})_{4}\right]_{0.54(1)}\left[\mathrm{Bi}_{6} \mathrm{O}_{5}(\mathrm{OH})_{3}\right]_{0.46(1)}\left(\mathrm{NO}_{3}\right)_{5.54(1)}{ }^{42}$ An alternative but more invasive method of isolation in this case would have been to load the injection system with a cold solvent and inject the solvent once the intermediate phase appears to rapidly cool down and quench the reaction. In conventional laboratory syntheses, usually reaction times of several hours or even days are used meaning that many intermediate phases which could potentially provide valuable information about reaction mechanisms are often overlooked.

\section{CONCLUSION}

A new flexible reactor setup, SynRAC, allowing for the analysis of chemical reactions under ambient and solvothermal reactions has been constructed. The setup is an aluminum casing that can accommodate two different sizes of borosilicate vessels routinely used in laboratory-scale syntheses. The reaction temperature is measured inside the reaction vessels via PTFE-coated thermocouples and can be controlled between ambient temperature and $180{ }^{\circ} \mathrm{C}$ with a deviation of \pm 0.6 ${ }^{\circ} \mathrm{C}$. An electromagnetic stirrer incorporated in the base plate offers the option of stirring the reaction mixture during the experiment. The setup furthermore features an injection system and a solid dosing device that can be used to inject up to two additives or one solid, respectively, during the reaction to, for instance, initiate very fast reactions or to quench reactions. The whole experiment including sample heating and cooling as well as injection steps is remote-controlled using a custom-programmed user interface based on LabView. Up to now, the reactor setup has been successfully tested for the analysis of reactions using $\mathrm{X}$-ray diffraction techniques to study crystallization kinetics, phase transformations, and intermediate phases. Furthermore three proof of concept studies were described which used the SynRAC setup.

\section{SUPPLEMENTARY MATERIAL}

See supplementary material for additional information regarding the reactor heating rate and the safety cap as well as more details on the two case studies described in Secs. III A and III B.

\section{ACKNOWLEDGMENTS}

Parts of this research were carried out at the beamlines P09, P08, and P02.1 at DESY, a member of the Helmholtz Association (HZG). We would like to thank Jörg Strempfer, the beamline staff of P09 as well as Martin Etter and the beamline staff of P02.1 and P08 for their assistance during the beamtimes. Furthermore we thank Helge Reinsch, Sebastian Leubner, and Jannick Jacobsen for their support as well as Mr. Busch of Galvano-T GmbH for his support in constructing the heating mantle of the reactor. This work has been supported by the MATsynCELL project through the Röntgen-Ångström Cluster, supported by the Swedish Research Council and the German Federal Ministry of Education and Research (BMBF).

${ }^{1}$ N. Pienack and W. Bensch, Angew. Chem. 123, 2062 (2011).

${ }^{2}$ Y. Shen, E. E. Pedersen, M. Christensen, and B. B. Iversen, Rev. Sci. Instrum. 85, 104103 (2014).

${ }^{3}$ H. H. M. Yeung, Y. Wu, S. Henke, A. K. Cheetham, D. O'Hare, and R. I. Walton, Angew. Chem. 128, 2052 (2016).

${ }^{4}$ E. D. Bøjesen and B. B. Iversen, CrystEngComm 18, 8332 (2016).

${ }^{5}$ G. Férey, M. Haouas, T. Loiseau, and F. Taulelle, Chem. Mater. 26, 299 (2014).

${ }^{6}$ M. Haouas, C. Volkringer, T. Loiseau, G. Férey, and F. Taulelle, Chem. Mater. 24, 2462 (2012).

${ }^{7} \emptyset$. B. Vistad, D. E. Akporiaye, F. Taulelle, and K. P. Lillerud, Chem. Mater. 15, 1639 (2003).

${ }^{8}$ H. Terraschke, L. Ruiz Arana, P. Lindenberg, and W. Bensch, Analyst 141, 2588 (2016).

${ }^{9}$ Y. Wu, S. Henke, G. Kieslich, I. Schwedler, M. Yang, D. A. X. Fraser, and D. O'Hare, Angew. Chem., Int. Ed. 55, 14081 (2016).

${ }^{10}$ R. I. Walton and D. O'Hare, Chem. Commun. 2000, 2283.

${ }^{11}$ E. Antonova, B. Seidlhofer, J. Wang, M. Hinz, and W. Bensch, Chem.-Eur. J. 18, 15316 (2012).

${ }^{12}$ M. Feyand, C. Näther, A. Rothkirch, and N. Stock, Inorg. Chem. 49, 11158 (2010).

${ }^{13}$ F. Millange, M. I. Medina, N. Guillou, G. Férey, K. M. Golden, and R. I. Walton, Angew. Chem., Int. Ed. 49, 763 (2010).

${ }^{14}$ R. Kiebach, N. Pienack, M.-E. Ordolff, F. Studt, and W. Bensch, Chem. Mater. 18, 1196 (2006).

${ }^{15}$ J. Keating, G. Sankar, T. I. Hyde, S. Kohara, and K. Ohara, Phys. Chem. Chem. Phys. 15, 8555 (2013).

${ }^{16}$ K. M. Ø. Jensen, M. Christensen, P. Juhas, C. Tyrsted, E. D. Bøjesen, N. Lock, S. J. L. Billinge, and B. B. Iversen, J. Am. Chem. Soc. 134, 6785 (2012).

${ }^{17}$ L. Soderholm and J. F. Mitchell, APL Mater. 4, 053212 (2016).

${ }^{18}$ L. Engelke, M. Schaefer, F. Porsch, and W. Bensch, Eur. J. Inorg. Chem. 2003, 506.

${ }^{19}$ J. Becker, M. Bremholm, C. Tyrsted, B. Pauw, K. M. O. Jensen, J. Eltzholt, M. Christensen, and B. B. Iversen, J. Appl. Crystallogr. 43, 729 (2010).

${ }^{20}$ R. J. Francis, S. O’Brien, A. M. Fogg, P. S. Halasyamani, D. O’Hare, T. Loiseau, and G. Férey, J. Am. Chem. Soc. 121, 1002 (1999).

${ }^{21}$ S. J. Moorhouse, N. Vranješ, A. Jupe, M. Drakopoulos, and D. O'Hare, Rev. Sci. Instrum. 83, 084101 (2012).

${ }^{22}$ J.-D. Grunwaldt, M. Ramin, M. Rohr, A. Michailovski, G. R. Patzke, and A. Baiker, Rev. Sci. Instrum. 76, 054104 (2005).

${ }^{23}$ N. Pienack, L. Ruiz Arana, W. Bensch, and H. Terraschke, Crystals 6, 157 (2016).

${ }^{24}$ O. H. Seeck, C. Deiter, K. Pflaum, F. Bertam, A. Beerlink, H. Franz, J. Horbach, H. Schulte-Schrepping, B. M. Murphy, M. Greve, and O. Magnussen, J. Synchrotron Radiat. 19, 30 (2012).

${ }^{25}$ M. Wendt, U. Warzok, C. Nather, J. van Leusen, P. Kogerler, C. A. Schalley, and W. Bensch, Chem. Sci. 7, 2684 (2016).

${ }^{26}$ T. Rhauderwiek, S. Waitschat, S. Wuttke, H. Reinsch, T. Bein, and N. Stock, Inorg. Chem. 55, 5312 (2016).

${ }^{27}$ H. Reinsch, J. Benecke, M. Etter, N. Heidenreich, and N. Stock, Dalton Trans. 46, 1397 (2017).

${ }^{28}$ S. Springer, N. Heidenreich, N. Stock, L. van Wüllen, K. Huber, S. Leoni, and M. Wiebcke, Z. Kristallogr.-Cryst. Mater. 232, 77 (2017).

${ }^{29}$ M. Wendt, L. K. Mahnke, N. Heidenreich, and W. Bensch, Eur. J. Inorg. Chem. 2016, 5393.

${ }^{30}$ N. Yuan, V. Pascanu, Z. Huang, N. Heidenreich, S. Leubner, A. K. Inge, J. Gaar, N. Stock, B. Martin-Matute, and X. Zou, "Probing the active catalytic species generated from MOF-supported $\mathrm{Pd}$ in $\mathrm{C}-\mathrm{C}$ coupling reactions: An operando X-ray absorption spectroscopy study,” (unpublished).

${ }^{31}$ J. H. Cavka, S. Jakobsen, U. Olsbye, N. Guillou, C. Lamberti, S. Bordiga, and K. P. Lillerud, J. Am. Chem. Soc. 130, 13850 (2008). 
${ }^{32}$ M. Lammert, M. T. Wharmby, S. Smolders, B. Bueken, A. Lieb, K. A. Lomachenko, D. D. Vos, and N. Stock, Chem. Commun. 51, 12578 (2015).

${ }^{33}$ M. Lammert, C. Glißmann, and N. Stock, Dalton Trans. 46, 2425 (2017).

${ }^{34}$ J. Strempfer, S. Francoual, D. Reuther, D. K. Shukla, A. Skaugen, H. Schulte-Schrepping, T. Kracht, and H. Franz, J. Synchrotron Radiat. 20, 541 (2013).

${ }^{35}$ A. P. Hammersley, S. O. Svensson, M. Hanfland, A. N. Fitch, and D. Hausermann, High Pressure Res. 14, 235 (1996).
${ }^{36}$ A. F. Gualtieri, Phys. Chem. Miner. 28, 719 (2001).

${ }^{37}$ H. Reinsch and N. Stock, CrystEngComm 15, 544 (2013).

${ }^{38}$ F. Niekiel, M. Ackermann, P. Guerrier, A. Rothkirch, and N. Stock, Inorg. Chem. 52, 8699 (2013).

${ }^{39}$ T. Ahnfeldt and N. Stock, CrystEngComm 14, 505 (2012).

${ }^{40}$ S. R. Sushrutha and S. Natarajan, Cryst. Growth Des. 13, 1743 (2013).

${ }^{41}$ M. Feyand, M. Köppen, G. Friedrichs, and N. Stock, Chem.-Eur. J. 19, 12537 (2013).

${ }^{42}$ A. N. Christensen and B. Lebech, Dalton Trans. 41, 1971 (2012). 